\title{
Improved hanger design for robustness of through-arch bridges
}

1 Rui-Juan Jiang BEng, MEng, PhD

Senior Engineer, The Research Centre, Shenzhen Municipal Engineering Design and Research Institute, Shenzhen, China; The School of Civil Engineering, Shandong University, Jinan, Shandong, China; Department of Civil Engineering, The University of Hong Kong, Hong Kong, China
2 Francis Tat Kwong Au BSc(Eng), MSc(Eng), PhD, MICE, FIStruct-E, FHKIE, CEng

Professor, Department of Civil Engineering, The University of Hong Kong, Hong Kong, China

3 Qi-Ming Wu BEng, MEng

Engineer, The Research Centre, Shenzhen Municipal Engineering Design and Research Institute, Shenzhen, China
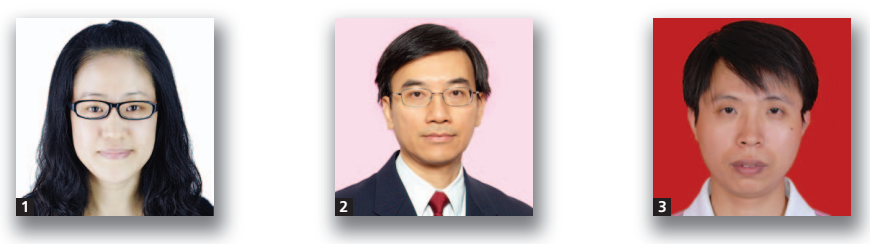

Hangers in through-arch bridges are important components since they suspend the entire bridge deck from the arch ribs. Local damage at a hanger may lead to subsequent damage of various components in the vicinity or even progressive collapse of the bridge. After reviewing the conventional design of double-hangers in through-arch bridges, this paper puts forward a new design approach. The suitability and robustness of this new approach are then verified by numerical simulation of a real bridge. The impact effects induced by local fracture of a hanger on the other structural members are then simulated by dynamic time-history analyses. The new approach of hanger design is shown to improve the structural robustness. In particular, when one or more hangers are damaged thereby causing local failure, the through-arch bridge will not be endangered and will still maintain reasonable overall load-carrying capacity so that the necessary emergency measures can be taken.

\section{Notation \\ $R_{\mathrm{d}}$ \\ $R_{\mathrm{i}}$ \\ $\delta_{\mathrm{t}}$ \\ $\eta$ \\ structural response under dead load structural response under hanger fracture duration of hanger fracture impact coefficient due to hanger fracture}

\section{Introduction}

A progressive collapse is a structural failure that is initiated by localised structural damage and subsequently develops, as a chain reaction, into a failure that involves a major portion of the structural system (Ellingwood and Dusenberry, 2005). The main feature of progressive collapse is that the total cumulative damage is disproportionate to the original cause (General Services Administration, 2003; Vlassis et al., 2006). It often means injury to people, damage to the environment or economic losses for the society. The progressive collapse of the Ronan Point Apartment Tower in Canning Town, London, UK in May 1968 illustrated a lack of provisions for general structural integrity or robustness in existing building codes. It also prompted efforts to enhance structural robustness in design codes in various countries (Pearson and Delatte, 2005).

As it is not feasible to foresee all possible sources of collapse initiation, a rational design approach to guard against progressive collapse should aim at controlling the consequences of local damage rather than just attempting to prevent damage on the whole. This can be achieved through structural robustness, which is related to the concept of progressive collapse. In EN199 1-1-7 Eurocode 1: Part 1-7 Accidental Actions (CEN, 2006), structural robustness is defined as 'the ability of a structure to withstand events like fire, explosions, impact or consequences of human error without being damaged to an extent disproportionate to the original cause'. There are various practical ways to achieve a robust structure, including an approach based on energy absorption (Beeby, 1999), an algorithm based on energy ratio (Smith, 2003) and so on. Others have found that robustness depends on a number of structural parameters, including strength of members and connections, ductility, energy absorption, provision of alternative load paths and resistance to fire and corrosion (Agarwal 
et al., 2006; Alexander, 2004; IStructE, 2002). Jiang and Chen (2008) also carried out a review on the progressive collapse and control design of building structures. According to Eurocode 1, the principle is that local damage is acceptable, provided that it will not endanger the structure and that the overall loadcarrying capacity is maintained during an appropriate length of time to allow the necessary emergency measures to be taken (Gulvanessian and Vrouwenvelder, 2006).

Hangers in through-arch bridges are important components since they suspend the entire bridge deck from the arch ribs. Local damage at a hanger may lead to subsequent damage of various components in the vicinity or even progressive collapse of the bridge. Real-time monitoring and diagnoses of the health condition of hangers have been conducted ( $\mathrm{Li}$ et al., 2007), although the state of the art is not yet fully reliable ( $\mathrm{Li}$ et al., 2008). After reviewing the conventional design of double-hangers in through-arch bridges, this paper puts forward a new design approach. The suitability and robustness of this new approach will then be verified by numerical simulation of a real bridge.

\section{Conventional design of arch bridge hangers}

Each hanger of a through-arch bridge is anchored to the arch rib at one end and a transverse beam at the other. The doublehanger anchorage (Figure 1) is often adopted instead of the single-hanger anchorage for convenience of hanger replacement. The two vertical hangers at the same anchorage are conventionally designed to be identical both in material and cross-section. As they are subject to approximately the same stress levels and variations as well as corrosive environment, they approach the end of their service lives at roughly the same time. When the slightly weaker hanger in the pair fails first, the resulting impact and hence overstress induced in the adjacent hanger will likely cause its immediate failure, damage other structural members in the vicinity and possibly lead to

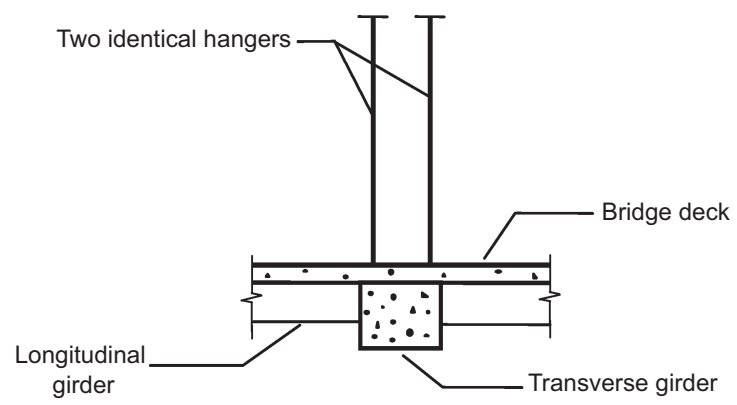

Figure 1. Conventional double-hanger anchorage with two identical hangers

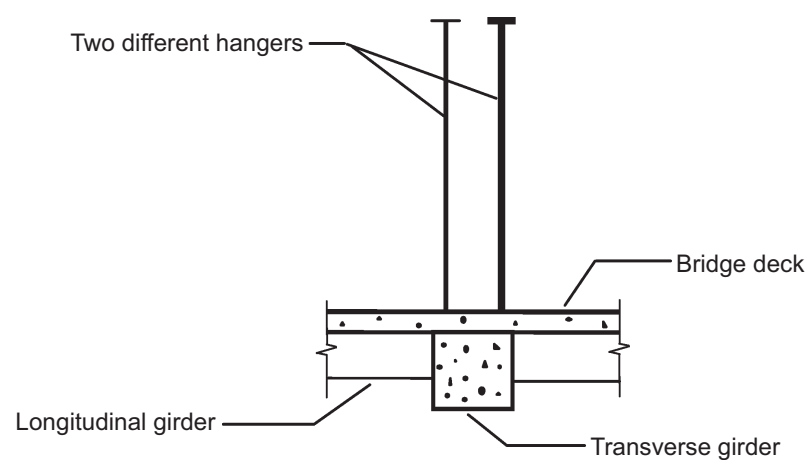

Figure 2. Improved double-hanger anchorage with two different hangers

progressive collapse. Therefore in these circumstances, the conventional design method improves neither the safety nor the convenience of hanger replacement.

\section{Improved design of arch bridge hangers}

To avoid the fracture of a hanger triggering the failure of another in the same group, it is desirable for hangers in the same group to be designed with different service lives. It is feasible to provide hangers of the same material but with different cross-sectional areas (Figure 2). With the use of different cross-sectional areas and appropriate control of initial hanger tension by proper jacking during erection, hangers in the same group will have different stress levels in spite of similar stress ranges subsequently, and therefore different service lives. The hanger with larger cross-section and lower stress level is expected to keep the arch bridge safe when the other hanger with smaller cross-section and higher stress level fails unexpectedly. The performance of this new design method will be studied numerically using a through-type arch bridge, namely Shenzhen North Railway Station Bridge, using the commercial software ANSYS (2010).

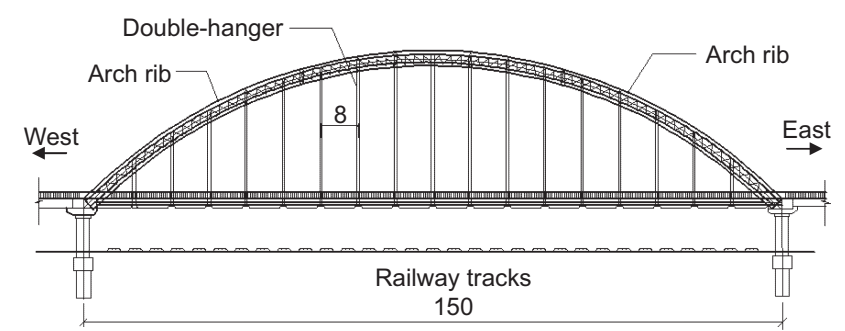

Figure 3. Elevation of the bridge analysed (unit: $\mathrm{m}$ ) 


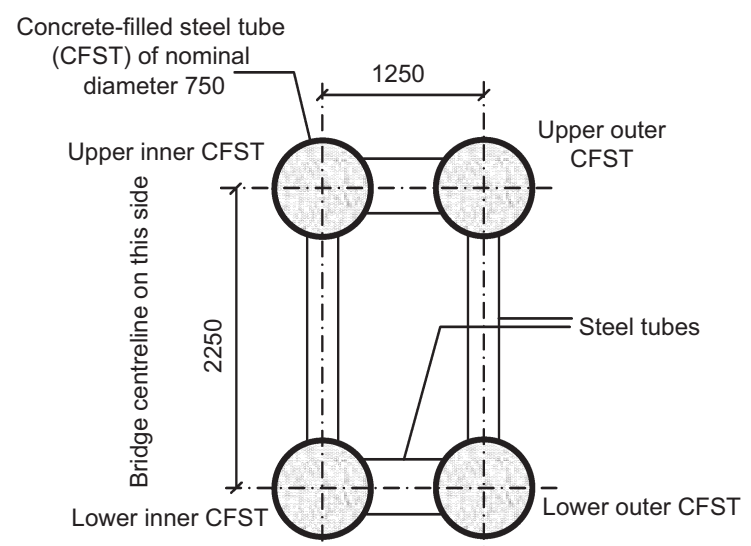

Figure 4. Cross-section of an arch rib (unit: $\mathrm{mm}$ )

\section{Modelling of the chosen bridge}

Shenzhen North Railway Station Bridge (Figure 3) in South China is a through-type tied arch bridge, which was built in 2000 , spanning $150 \mathrm{~m}$ over a total of 29 railway tracks. The bridge has a span-rise ratio of $4 \cdot 5$. The width of deck is $23 \cdot 5 \mathrm{~m}$. Horizontal cables are installed in the longitudinal steel box girders of the deck to provide the necessary tie forces. The bridge has two vertical arch ribs tied to the piers and each rib is composed of four concrete-filled steel tubes having a lattice girder section of $2.0 \mathrm{~m}$ in width and $3.0 \mathrm{~m}$ in height (Figure 4). There are 17 conventional vertical double-hanger anchorages for each arch rib at spacing of $8.0 \mathrm{~m}$. The spacing between hangers in each anchorage is $0.48 \mathrm{~m}$. The composite bridge deck consists of concrete slabs supported on a steel grid comprising two longitudinal steel girders and 17 transverse steel girders. The material properties of the bridge are listed in Table 1. More details about this bridge are found in Li et al. (2002). The bridge has been providing satisfactory service so far. Figure 5 shows the three-dimensional (3D) finite-element model developed using the commercial package ANSYS.

The concrete-filled steel tubes are modelled by the regular 3D Euler-Bernoulli beam elements BEAM4 with equivalent crosssectional and material properties, namely cross-sectional area of $0.58 \mathrm{~m}^{2}$, modulus of elasticity of $34.5 \mathrm{GPa}$, moment of inertia of
$0.02495 \mathrm{~m}^{4}$, torsional moment of inertia of $0.04816 \mathrm{~m}^{4}$, Poisson's ratio of $0 \cdot 2$ and density of $2160 \cdot 55 \mathrm{~kg} / \mathrm{m}^{3}$. The BEAM4 elements are also adopted to model the arch rib bracings, the longitudinal steel box girders, the steel tubes connecting the four concrete-filled steel tubes of each arch rib. The transverse steel girders of the bridge deck are modelled using the 3D Timoshenko beam elements BEAM188, which are provided with an additional degree of freedom at each node to cope with warping. The concrete slabs of the bridge deck are modelled as equivalent planar space frames by grillage analogy using BEAM4 elements. The hangers are modelled by the 3D spar elements LINK8 that can take axial forces only. The crosssectional properties of these components, except those of the transverse girders, are listed in Table 2. The BEAM188 element of ANSYS needs the cross-section shape and dimensions as input information for automatic calculations. The connections between the longitudinal box girders and transverse girders, and between the concrete slabs and all steel girders (Figure 5) are all regarded as rigid connections and modelled by the multipoint constraint elements MPC184. There are 4672 elements and 2448 nodes in total in this $3 \mathrm{D}$ finite-element model. In this bridge, the arches are fixed rigidly to the piers, which are effectively tied together by horizontal cables. Since the boundary conditions of the arch ribs above the piers have negligible effect on dynamic analysis by this 3D finite-element model, the ends of the arch ribs can be treated as effectively fixed in all degrees of freedom, while the horizontal cables are ignored. The two longitudinal steel box girders are supported on transverse beams located at the piers. For convenience, the anchorages of each arch rib are numbered from 1 to 17 from west to east. The two hangers at each anchorage are numbered as a and $b$ for the north arch rib, and $\mathrm{a}^{\prime}$ and $\mathrm{b}^{\prime}$ for the south arch rib (Figure 6). The baseline finite-element model is developed by adjusting the initial lengths and forces of hangers by iteration so that the bridge geometry under permanent loading agrees with that shown on the illustrations.

\section{Impact effect due to hanger fracture}

Consider a double-hanger anchorage comprising two identical hangers. In case one of the hangers fractures, simplified static analysis predicts that the other hanger will have its tensile stress doubled. However, rigorous dynamic analysis predicts

\begin{tabular}{lcccccc}
\hline Material & $\begin{array}{c}\text { Modulus of } \\
\text { elasticity: GPa }\end{array}$ & $\begin{array}{c}\text { Coefficient of } \\
\text { expansion: } \times 10^{-5}\end{array}$ & $\begin{array}{c}\text { Poisson's } \\
\text { ratio }\end{array}$ & $\begin{array}{c}\text { Shear modulus: } \\
\mathrm{GPa}\end{array}$ & $\begin{array}{c}\text { Density: } \\
\mathrm{kg} / \mathrm{m}^{3}\end{array}$ & \begin{tabular}{l} 
Yield stress: MPa \\
\hline Concrete
\end{tabular} \\
Steel & $34 \cdot 5$ & $1 \cdot 0$ & $0 \cdot 2$ & $14 \cdot 375$ & 2500 & - \\
Hanger & 206 & $1 \cdot 2$ & $0 \cdot 3$ & $79 \cdot 231$ & 7850 & 340 \\
\end{tabular}

Table 1. Material properties of the bridge analysed 


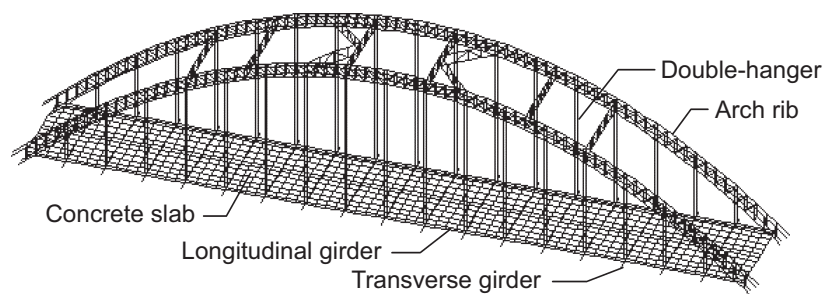

Figure 5. Finite-element model of the bridge analysed

the stress in the other hanger to over-shoot beyond the increased static stress value and oscillate for a while before becoming steady again. If this maximum stress in the other hanger due to transient impact effects is high enough to fracture this hanger, it may cause progress failure of the whole structure. To ensure the robustness of an arch bridge, one should first assess the impact effect caused by sudden hanger fracture on components in the vicinity and the remaining structure. To simulate the sudden fracture of a hanger, the member is omitted from the model and replaced by the steady internal forces in service there (Figure 7), which are then assumed to decrease linearly to zero within a duration $\delta_{\mathrm{t}}$ as described in Section 5.1. The impact effect due to hanger fracture is studied by carrying out dynamic analysis using the $3 \mathrm{D}$ finite-element model. The time step for dynamic analysis is taken as $0 \cdot 05 \delta_{\mathrm{t}}$ within the duration of hanger fracture and $0.01 \mathrm{~s}$ thereafter. For convenience, Rayleigh damping (Bathe, $1996)$ is assumed with the damping ratio taken as $0 \cdot 02$. The impact coefficient $\eta$ is defined as

1. $H=\left(R_{\mathrm{d}}+R_{\mathrm{i}}\right) / R_{\mathrm{d}}$ where $R_{\mathrm{d}}$ is the structural response under dead load and $R_{\mathrm{i}}$ is the maximum structural response owing to hanger fracture only. The structural response of the bridge may take the form of stresses, bending moments, axial forces, displacements and so on. The contribution of vehicular live load to the structural response is ignored in comparison with the more significant dead load effects.

\subsection{Appropriate value for duration of hanger fracture $\delta_{\mathrm{t}}$}

In order to determine the appropriate value for the duration of hanger fracture $\delta_{\mathrm{t}}$ for the subsequent analyses, the relationship between the impact coefficient $\eta$ and the duration of hanger fracture $\delta_{\mathrm{t}}$ was studied. In view of symmetry, anchorages 1 to 9 were chosen for further analysis. At each of the anchorages, it was assumed that fracture occurred to one of the hangers in the group within different values of duration of hanger fracture $\delta_{\mathrm{t}}$, and the impact coefficient $\eta$ of the other hanger in the group was evaluated from dynamic analysis. The relationship between impact coefficient $\eta$ and duration of hanger fracture $\delta_{\mathrm{t}}$ is plotted in Figure 8 for the fracture of selected hangers, including the shortest hanger 1a, the second shortest hanger $1 \mathrm{~b}$, the medium length hanger $5 \mathrm{a}$ and the longest hanger $9 \mathrm{a}$.

Figure 8 shows that all $\eta-\delta_{\mathrm{t}}$ curves have essentially the same trend. In general, the impact effect due to hanger fracture increases when the duration of hanger fracture $\delta_{\mathrm{t}}$ decreases, but it tends to stabilise when $\delta_{\mathrm{t}}$ becomes $0.01 \mathrm{~s}$ or smaller. In other words, convergent results of impact can be obtained if a value of $\delta_{\mathrm{t}}$ not exceeding $0.01 \mathrm{~s}$ is chosen. Therefore in the subsequent analyses, $\delta_{\mathrm{t}}$ is taken as $0.001 \mathrm{~s}$. When $\delta_{\mathrm{t}}$ exceeds $1 \cdot 0 \mathrm{~s}$, it also tends to decrease to a relatively stable value as the slow action can be regarded as largely static in nature. In

\begin{tabular}{|c|c|c|c|c|}
\hline Components & $\begin{array}{l}\text { Cross-sectional area: } \\
\quad \times 10^{-3} \mathrm{~m}^{2}\end{array}$ & $\begin{array}{l}\text { In-plane moment of } \\
\text { inertia: } \times 10^{-3} \mathrm{~m}^{4}\end{array}$ & $\begin{array}{l}\text { Out-of-plane } \\
\text { moment of inertia: } \\
\quad \times 10^{-3} \mathrm{~m}^{4}\end{array}$ & $\begin{array}{l}\text { Torsional moment of } \\
\text { inertia : } \times 10^{-3} \mathrm{~m}^{4}\end{array}$ \\
\hline Longitudinal girder & $32 \cdot 00$ & $2 \cdot 1010$ & $4 \cdot 607$ & $4 \cdot 500$ \\
\hline Horizontal connecting tube & $12 \cdot 25$ & $0 \cdot 2331$ & $0 \cdot 2331$ & $0 \cdot 4662$ \\
\hline Vertical connecting tube & $7 \cdot 383$ & $0 \cdot 0511$ & $0 \cdot 0511$ & $0 \cdot 1021$ \\
\hline Inclined connecting tube & $7 \cdot 383$ & 0.0511 & 0.0511 & $0 \cdot 1021$ \\
\hline Horizontal bracing tube & $15 \cdot 39$ & $0 \cdot 4622$ & $0 \cdot 4622$ & 0.9244 \\
\hline Inner bracing tube & $7 \cdot 314$ & 0.0775 & 0.0775 & $0 \cdot 1549$ \\
\hline Longitudinal grillage member of slab & $639 \cdot 7$ & $11 \cdot 610$ & $32 \cdot 02$ & $19 \cdot 96$ \\
\hline Transverse grillage member of slab & $480 \cdot 0$ & $9 \cdot 2710$ & $9 \cdot 271$ & $21 \cdot 58$ \\
\hline Hanger & $2 \cdot 348$ & - & - & - \\
\hline
\end{tabular}




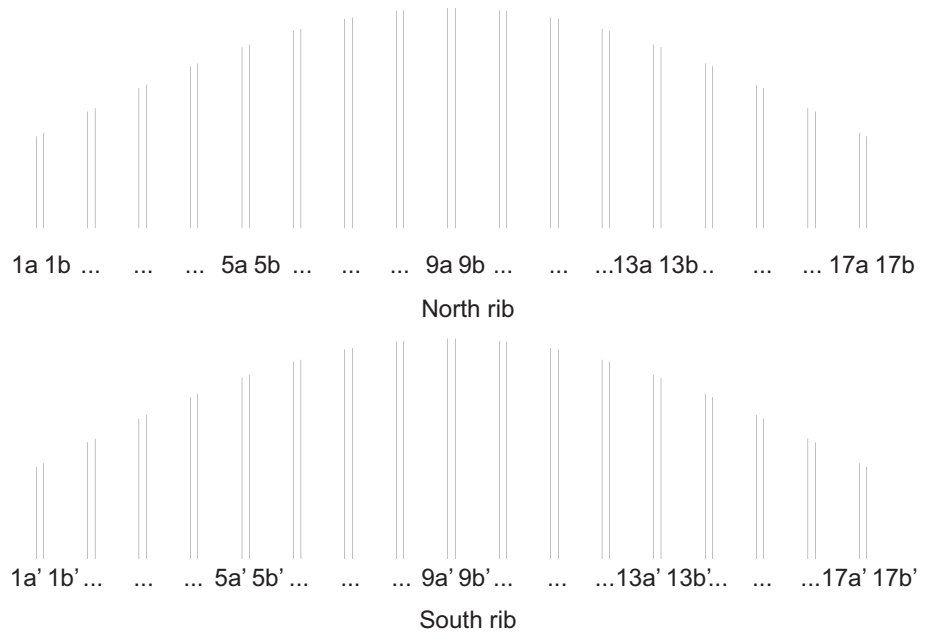

Figure 6. Numbering of hangers in north and south ribs

particular, Figure 8 shows the impact coefficients at the surviving hangers $1 \mathrm{~b}, 1 \mathrm{a}, 5 \mathrm{~b}$ and $9 \mathrm{~b}$ when each of hangers $1 \mathrm{a}, 1 \mathrm{~b}, 5 \mathrm{a}$ and $9 \mathrm{a}$ is fractured respectively, and the corresponding maximum impact coefficients are 1.71, 1.63, 1.45 and 1.42. One may therefore conclude in general that, the shorter the hanger group is, the higher is the impact effect. One may next focus on the group comprising the shortest hanger 1a and second shortest hanger $1 \mathrm{~b}$. The impact effect $(\eta=1 \cdot 71)$ on $1 \mathrm{a}$ induced by the fracture of hanger $1 \mathrm{~b}$ is higher than that $(\eta=$ 1.63 ) on $1 \mathrm{~b}$ induced by the fracture of hanger 1a, as hanger 1a is shorter than hanger $1 \mathrm{~b}$. Hence at the same anchorage, the longer hanger should be designed with a longer service life compared to the shorter one.

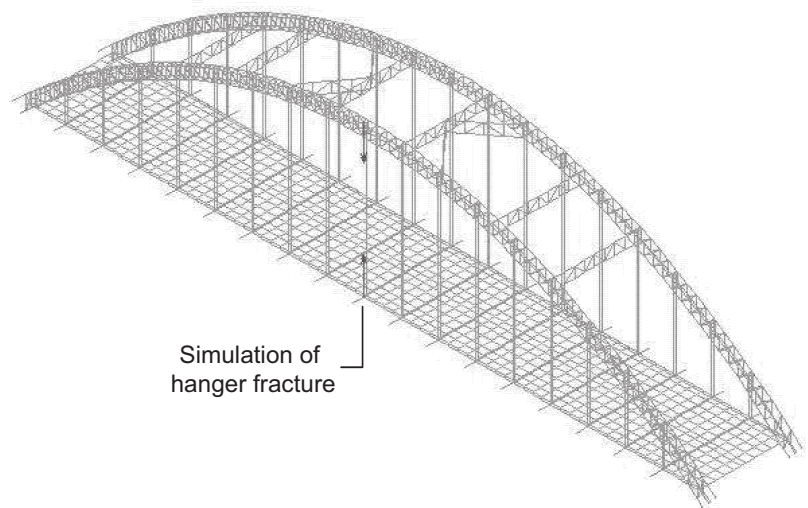

Figure 7. Simulation of hanger fracture

\subsection{Impact effect on various members owing to hanger fracture}

The fracture of hanger $1 \mathrm{~b}$ of the north rib was chosen for further study to identify the impact effects on other structural components. The impact coefficients of the other hangers in the north and south ribs are shown in Figures 9 and 10 respectively. They confirm that the impact effects are mainly experienced by hangers in the vicinity of $1 \mathrm{~b}$ with a maximum impact coefficient of 1.70 experienced by hanger 1a, while those under the opposite rib are hardly affected. Figures 11 and 12 show the maximum impact coefficients of the upperouter concrete-filled steel tubes (Figure 4) in the north and south ribs respectively. They also confirm that the impact effects are confined to the parts of north rib in the vicinity and that the effects are quite mild with a maximum impact

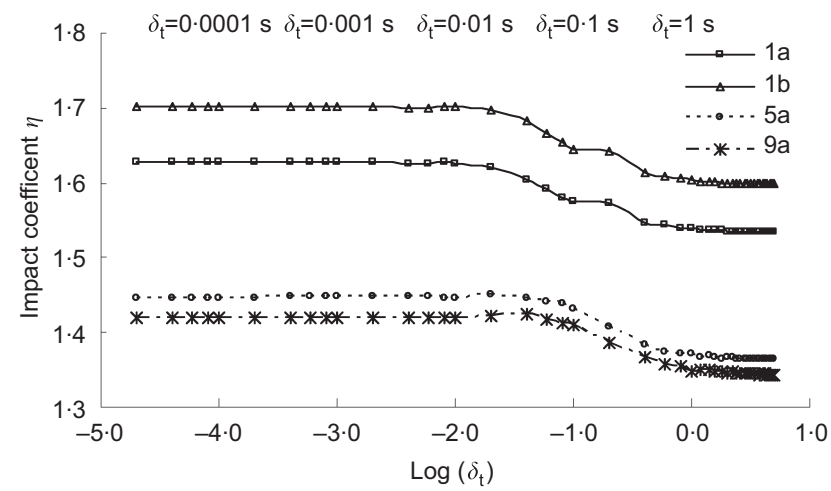

Figure 8. Relationship between impact coefficient and duration of hanger fracture 


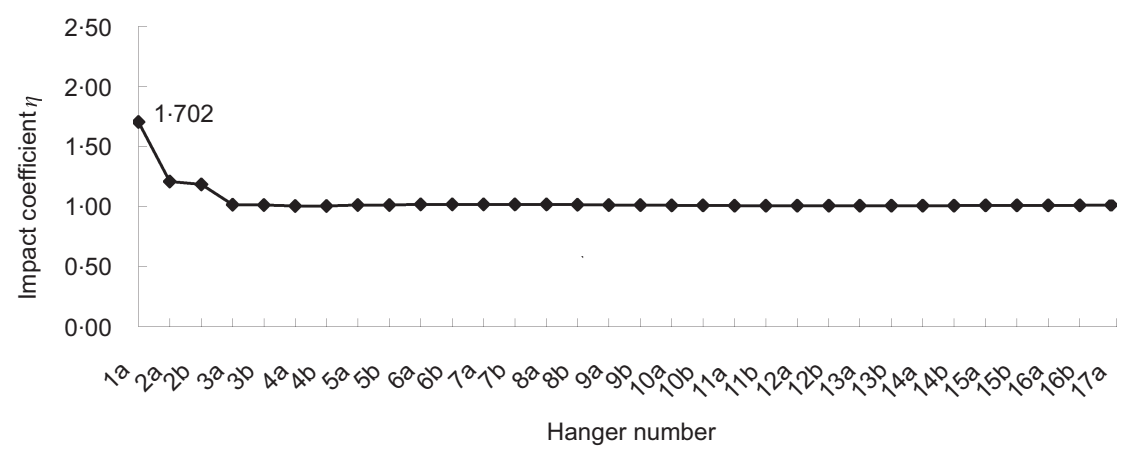

Figure 9. Impact coefficients of hangers in north rib when hanger $1 \mathrm{~b}$ fractures

coefficient of $1 \cdot 07$, while the south rib is hardly affected. The conclusion drawn is that the remaining hanger paired with a fractured hanger suffers the major part of the impact effect, while the effects on the other parts of the structure are minimal. Therefore the hangers should be so designed to avoid successive damage should any hanger happen to fracture.

When the hangers at a certain anchorage happen to fracture, the support conditions of the longitudinal girders will be affected. To assess the behaviour of the longitudinal girders when hanger $1 \mathrm{~b}$ fractures, the maximum normal stresses of the north and south longitudinal girders of the bridge are calculated and shown in Figures 13 and 14 respectively. It is noted that the maximum normal stress levels of the two longitudinal girders under service loading are around $20 \mathrm{MPa}$, which are far below the allowable stress of $210 \mathrm{MPa}$. However, when hanger $1 \mathrm{~b}$ happens to fracture, the most affected part of longitudinal girder in the vicinity has maximum normal stress exceeding $40 \mathrm{MPa}$, although it is still much lower than the allowable stress. Obviously when both hangers at the same anchorage fracture at the same time, the longitudinal girder will be significantly affected as the load path is substantially altered. In the original structure, the bridge deck is primarily supported by the transverse girders which are suspended from the hangers. Once a group of hangers is fractured, the corresponding transverse girder will then be carried by the longitudinal girder, thereby inducing substantial bending in it. The other parts of the longitudinal girder further away from the damage and the opposite longitudinal girder are also hardly affected.

\section{Robustness study of conventional and improved designs}

In order to demonstrate the robustness of the new improved hanger design method, a comparison is carried out using the same bridge. According to the original design, each hanger of the bridge is composed of 61 parallel prestressing steel wires of $7 \mathrm{~mm}$ diameter (i.e. 61- $\Phi 7$ ), with characteristic tensile strength of $1670 \mathrm{MPa}$ and a total cross-sectional area of $2348 \mathrm{~mm}^{2}$. The design code for highway cable-stayed bridges

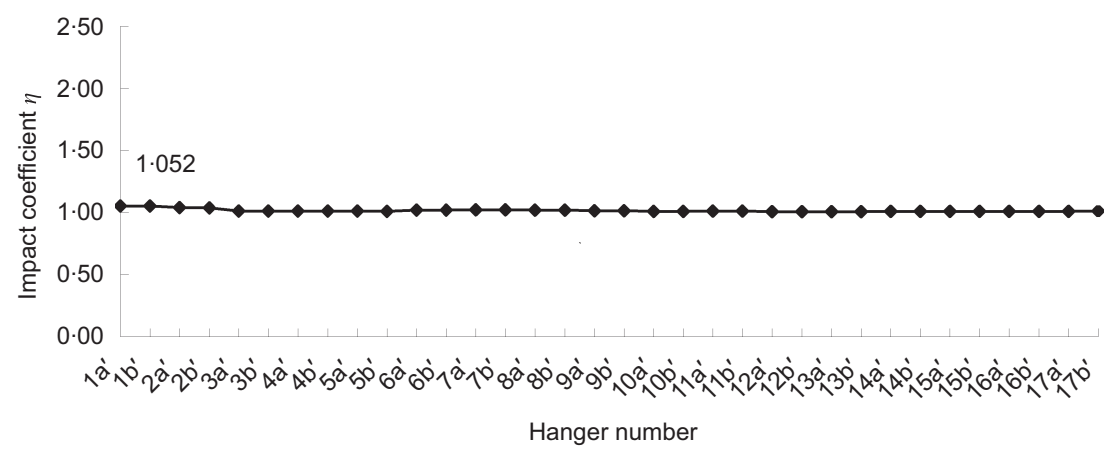

Figure 10. Impact coefficients of hangers in south rib when hanger

$1 \mathrm{~b}$ fractures 


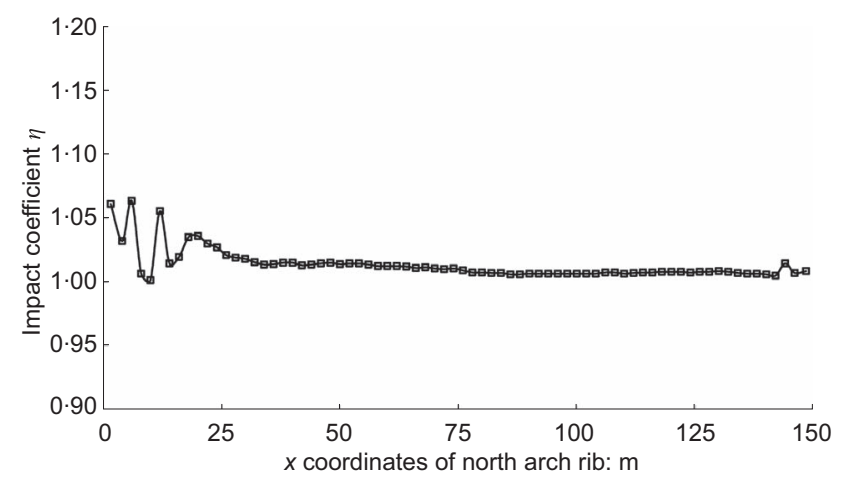

Figure 11. Impact coefficients of upper-outer tube in north rib when hanger $1 \mathrm{~b}$ fractures

in China (MTPRC, 2007) specifies the factors of safety for permanent and temporary situations to be 2.5 and $2 \cdot 0$ respectively for prestressing steel wires and strands. Therefore the allowable stresses of the prestressing steel wires are $668 \mathrm{MPa}$ and $835 \mathrm{MPa}$ for permanent and temporary situations respectively.

Based on the new method of robust hanger design put forward in this paper, the two hangers at the same anchorage are designed differently while maintaining roughly the same total cross-sectional area using 7-wire strands which are more commonly available on the market. The smaller hanger comprises 13 7-wire strands spun from $5 \mathrm{~mm}$ prestressing steel wires (i.e. 13-7Ф5) with a total cross-sectional area of $1787 \mathrm{~mm}^{2}$, while the bigger one is made of 20-7Ф5 prestressing steel strands with a total cross-sectional area of $2749 \mathrm{~mm}^{2}$. The characteristic tensile strength of prestressing steel strands is $1860 \mathrm{MPa}$. Using

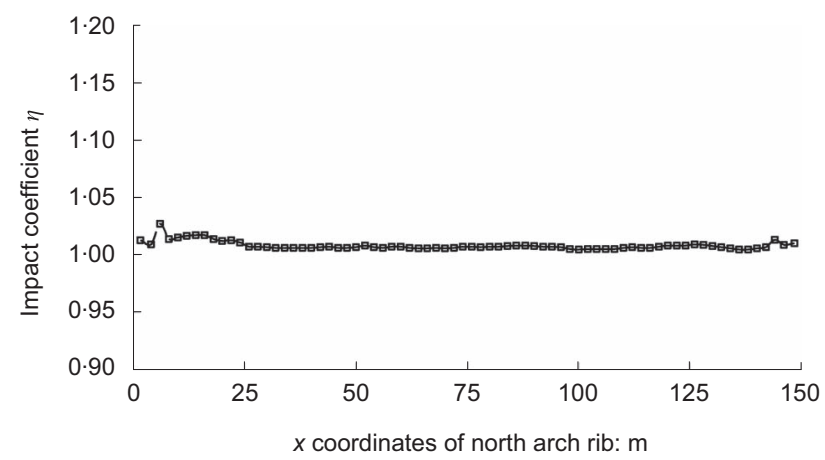

Figure 12. Impact coefficients of upper-outer tube in south rib when hanger $1 \mathrm{~b}$ fractures

the same factors of safety (MTPRC, 2007), the allowable stresses are $744 \mathrm{MPa}$ and $930 \mathrm{MPa}$, respectively, for permanent and temporary situations. While the total cross-sectional area of the group of hangers of $4536 \mathrm{~mm}^{2}$ in the improved design is smaller than $4696 \mathrm{~mm}^{2}$ in the original design, this is more than offset by the higher characteristic tensile strength of prestressing steel strands. Each anchorage of the improved hanger design is to carry the same total tensile force as in the original design, except that the ratio of stress in the smaller hanger to that in the bigger hanger due to permanent loading is controlled to be approximately $2 \cdot 0$ by proper jacking during erection of the bridge. The maximum stresses in the hangers of the improved design due to all expected loading are also checked to ensure that the necessary factors of safety are provided. The baseline finiteelement model of the bridge with the improved hanger design is similarly developed to achieve the required bridge geometry under permanent loading.

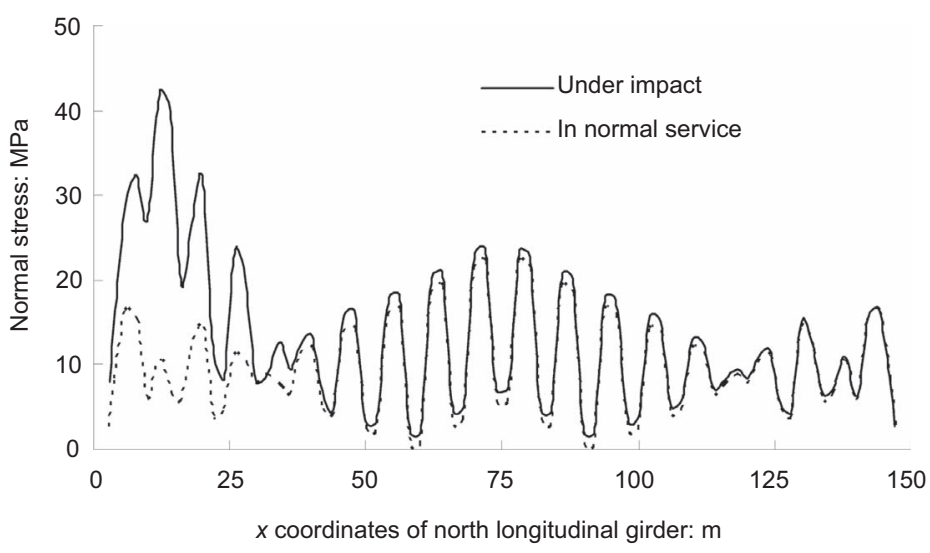

Figure 13. Maximum normal stresses of north longitudinal girder when hanger $1 \mathrm{~b}$ fractures 


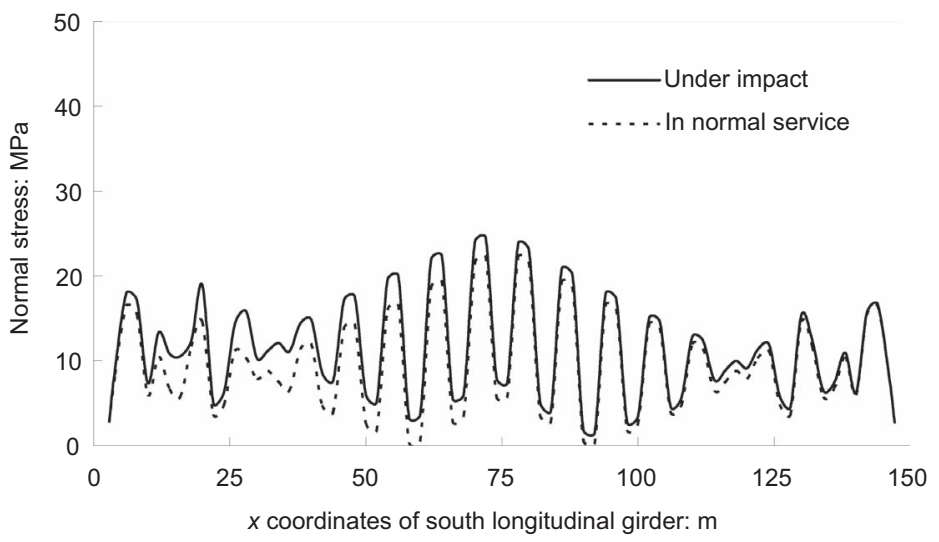

Figure 14. Maximum normal stresses of south longitudinal girder when hanger $1 \mathrm{~b}$ fractures

The modified arrangement of the hangers is described here Referring to Figure 6, hangers $1 \mathrm{a}$ to $17 \mathrm{a}$ and $1 \mathrm{~b}^{\prime}$ and $17 \mathrm{~b}^{\prime}$ are provided with the smaller section of 13-7Ф5, while hangers $1 \mathrm{~b}$ to $17 \mathrm{~b}$ and $1 \mathrm{a}^{\prime}$ to $17 \mathrm{a}^{\prime}$ are provided with the bigger section of 20-7Ф5. One may notice that this arrangement of the hangers is symmetrical neither about the longitudinal centreline nor about the transverse centreline. As the hangers of smaller sections are more prone to fracture, in case one or both of the smaller hangers carrying a transverse girder happen to fracture, the remaining bigger hangers can still provide effective support to the deck slab along a diagonal of the transverse girder in plan (e.g. a line joining the anchorages of hangers $5 \mathrm{~b}$ and $\left.5 \mathrm{a}^{\prime}\right)$.

Table 3 shows six representative cases of hanger fracture that may happen to the bridge of conventional and improved hanger designs. The adjacent hangers most affected by the fracture are identified and monitored for their maximum stress increase. The factor of safety of a monitored hanger is then calculated as the ratio of its tensile strength to the maximum stress that occurs after fracture. As hangers in a group in the conventional design have identical sections, the worst scenario of simultaneous hanger fracture in a group is considered. The fracture of the smaller hanger in the same anchorage of improved design is considered for comparison with the conventional hanger design.

Case 1 deals with fracture at anchorage 1 with the shortest hangers, namely fracture of hangers $1 \mathrm{a}$ and $1 \mathrm{~b}$ for conventional design, and hanger 1a for improved design. Case 2 deals with fracture at anchorage 5 with medium-length hangers, namely fracture of hangers $5 \mathrm{a}$ and $5 \mathrm{~b}$ for conventional design, and hanger 5a for improved design. Case 3 deals with fracture at anchorage 9 with the longest hangers, namely fracture of hangers $9 \mathrm{a}$ and $9 \mathrm{~b}$ for conventional design, and hanger $9 \mathrm{a}$ for improved design. Case 4 deals with fracture at both anchorages 1 and 17 with the shortest hangers, namely fracture of hangers $1 \mathrm{a}, 1 \mathrm{~b}, 17 \mathrm{a}$ and $17 \mathrm{~b}$ for conventional design, and hangers $1 \mathrm{a}$

\begin{tabular}{|c|c|c|c|c|c|c|c|}
\hline \multirow[b]{2}{*}{ Case } & \multicolumn{2}{|c|}{ Fractured hangers } & \multicolumn{2}{|c|}{ Monitored hangers } & \multicolumn{3}{|c|}{ Factor of safety } \\
\hline & Conventional & Improved & Conventional & Improved & Conventional & Improved & Increase \\
\hline 1 & $1 a, 1 b$ & $1 a$ & $2 a$ & $1 b$ & $3 \cdot 13$ & $3 \cdot 84$ & $22 \cdot 7 \%$ \\
\hline 2 & $5 a, 5 b$ & $5 a$ & $4 b$ & $5 b$ & $3 \cdot 36$ & $3 \cdot 82$ & $13 \cdot 7 \%$ \\
\hline 3 & $9 a, 9 b$ & $9 a$ & $8 b, 10 a$ & $9 b$ & $3 \cdot 53$ & $3 \cdot 84$ & $8 \cdot 7 \%$ \\
\hline 4 & $1 a, 1 b, 17 a, 17 b$ & $1 a, 17 a$ & $2 a, 16 b$ & $16 a$ & $3 \cdot 10$ & $3 \cdot 82$ & $23 \cdot 2 \%$ \\
\hline 5 & $5 a, 5 b, 13 a, 13 b$ & $5 a, 13 a$ & $4 b, 14 a$ & $14 a$ & $3 \cdot 29$ & $3 \cdot 79$ & $13 \cdot 2 \%$ \\
\hline 6 & $9 a, 9 b, 9 a^{\prime}, 9 b^{\prime}$ & $9 a, 9 b^{\prime}$ & $8 b, 10 a, 8 b^{\prime}, 10 a^{\prime}$ & $10 a, 8 b^{\prime}$ & $3 \cdot 43$ & $3 \cdot 82$ & $11 \cdot 8 \%$ \\
\hline
\end{tabular}

Table 3. Factors of safety at most affected hangers for various cases 


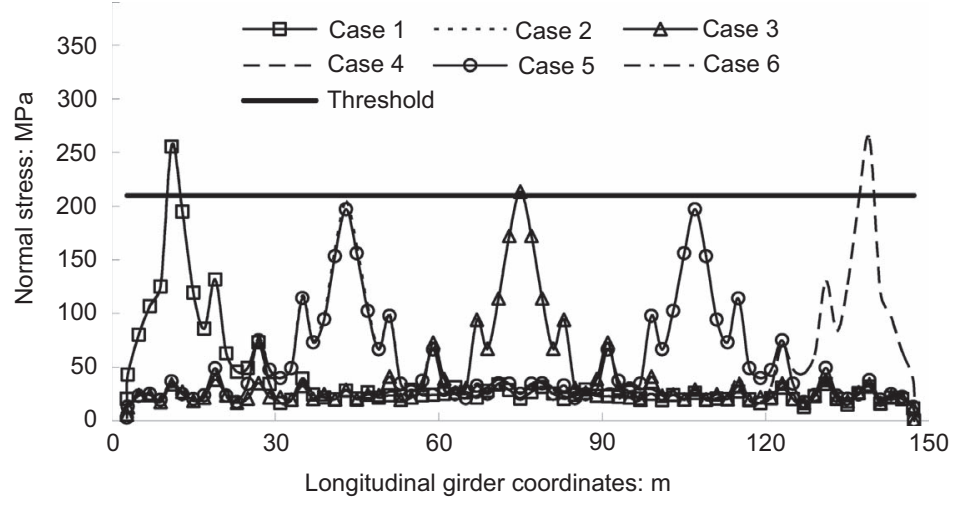

Figure 15. Maximum normal stresses of north longitudinal girder for fracture of hangers of conventional design

and $17 \mathrm{a}$ for improved design. Case 5 deals with fracture at both anchorage 5 and 13 with medium-length hangers, namely fracture of hangers $5 \mathrm{a}, 5 \mathrm{~b}, 13 \mathrm{a}$ and $13 \mathrm{~b}$ for conventional design, and hangers 5a and 13a for improved design. Case 6 deals with fracture at anchorage 9 with the longest hangers in both ribs, namely fracture of hangers $9 a, 9 b, 9 a^{\prime}$ and $9 b^{\prime}$ for conventional design, and hangers $9 \mathrm{a}$ and $9 \mathrm{~b}^{\prime}$ for improved design. The six cases are rather stringent tests of robustness as many of them involve simultaneous fracture of more than one hanger.

From the factors of safety shown in Table 3, one can draw various conclusions. All the calculated factors of safety are well above the minimum value of $2 \cdot 0$ for temporary situations (MTPRC, 2007). The factors of safety of cases 4 to 6 are slightly lower than those of cases 1 to 3, namely their corresponding cases with half the number of fractured hangers. Adopting the improved method of hanger design leads to higher factors of safety compared to those of conventional design. To a certain extent, this is caused by the use of 7 -wire strands having characteristic tensile strength of $11 \%$ higher than that of prestressing steel wires in the original design. Taking into account the characteristic tensile strength and cross-sectional area of each hanger group, the improved hanger group is only $7 \cdot 6 \%$ stronger than the conventional hanger group. Actually, the increases in factor of safety shown

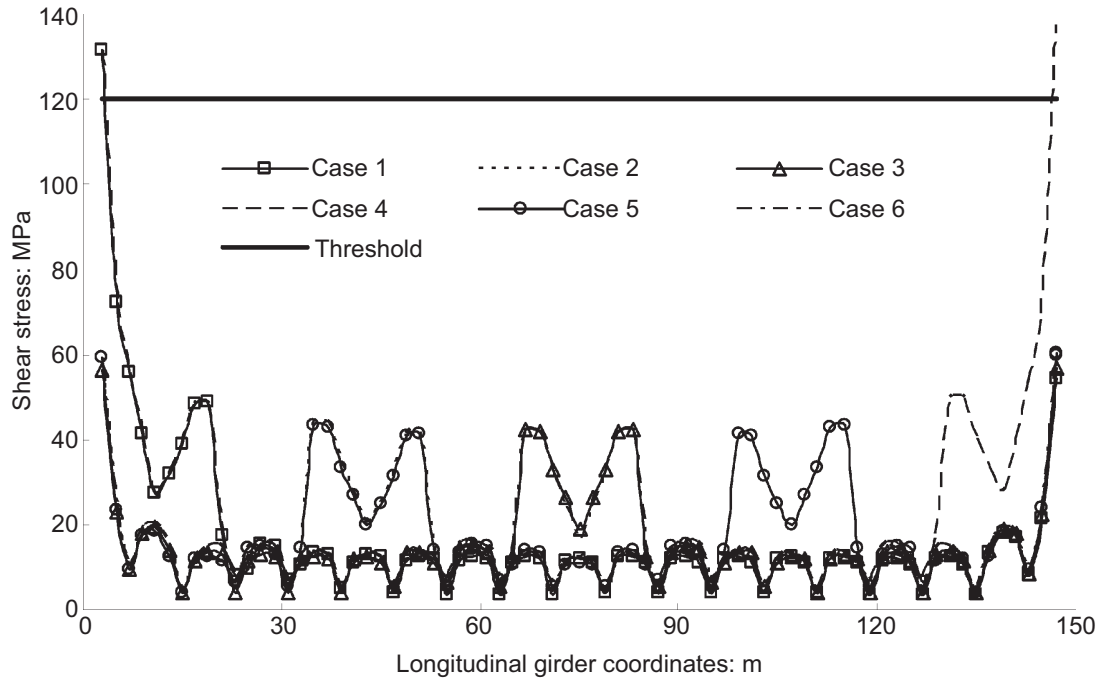

Figure 16. Maximum shear stresses of north longitudinal girder for fracture of hangers of conventional design 


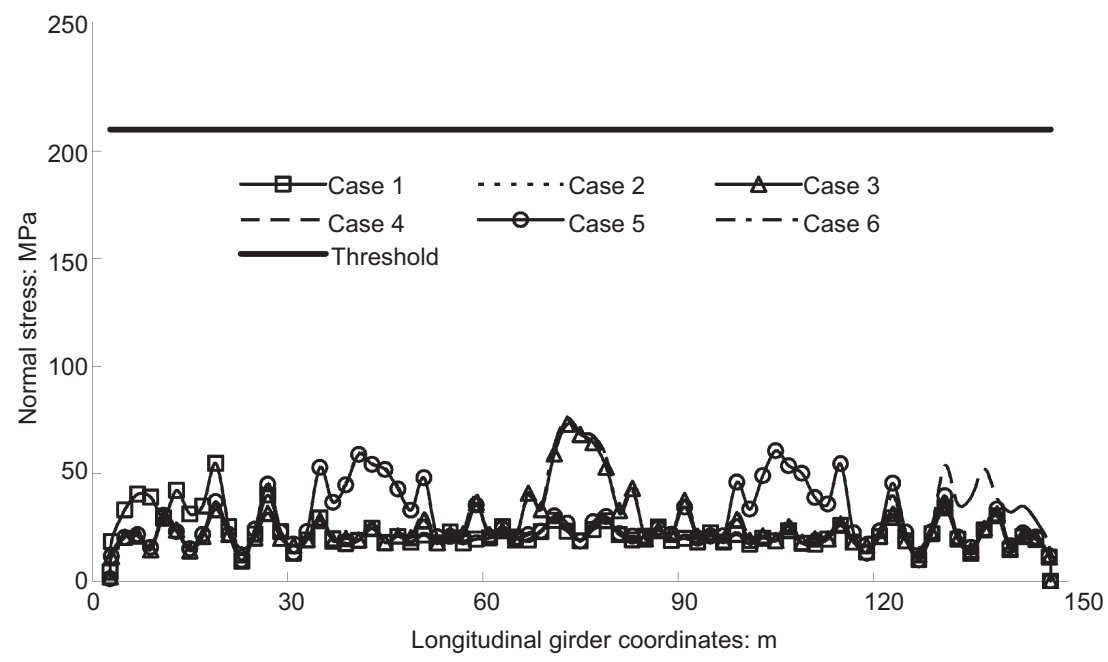

Figure 17. Maximum normal stresses of north longitudinal girder for fracture of hangers of improved design

in the last column of Table 3 are all above $7 \cdot 6 \%$. In addition, one should bear in mind that the hangers monitored for the conventional design are typically $8 \mathrm{~m}$ from the fractured hangers, such that the impact effect is relatively insignificant. In the improved hanger design, each hanger monitored has a fractured hanger in the same group and hence the impact effect is the most significant. One may therefore conclude that, when sudden hanger fracture happens, the improved hanger design can make the arch bridge safer and significant alteration of the load path is more remote.
The effects of hanger fracture on the north longitudinal steel girder are also assessed. Figures 15 and 16 show the maximum normal stresses and maximum shear stresses, respectively, of the north longitudinal steel girder for various cases of fracture of hangers of the conventional design, while those for the improved design are shown in Figures 17 and 18 respectively. Figure 15 shows that, for all of the six representative cases of hanger fracture, the normal stresses at the most affected parts of longitudinal girder either approach or even exceed the allowable normal stress of $210 \mathrm{MPa}$ in accordance with the

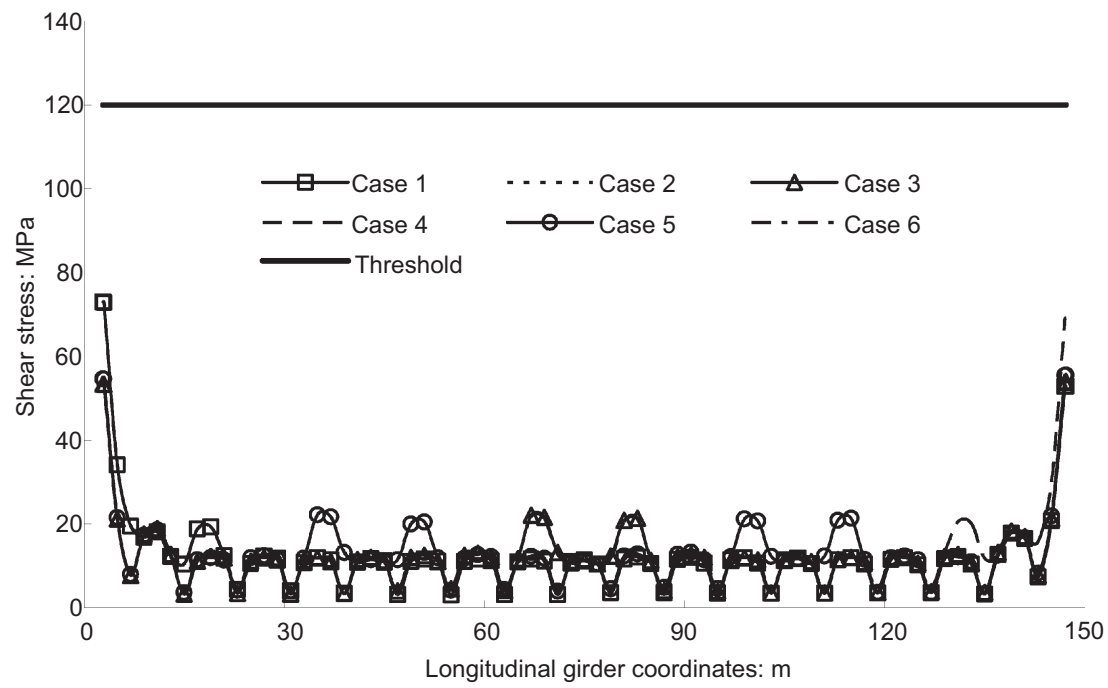

Figure 18. Maximum shear stresses of north longitudinal girder for fracture of hangers of improved design 
relevant design code (MOHURD, 2003), if the hangers have been designed by the conventional method. Similarly, Figure 16 shows that, for cases 1 and 4 of hanger fracture, the allowable shear stress of $120 \mathrm{MPa}$ is exceeded at certain parts adjacent to the fractured hangers. To sum up, if the hangers have been designed by the conventional method, simultaneous fracture of both hangers in a group is a real threat that must be considered, and the resulting alteration of load path does affect the stresses in the longitudinal girders. If any part of the longitudinal girders happens to fail because of the resulting overstressing, progressive failure may be triggered. Figures 17 and 18 show that, when hanger fracture happens to the bridge with the improved hanger design, the maximum normal stresses and maximum shear stresses of the longitudinal girder are well below the respective allowable values. This means that the longitudinal girders still have sufficient safety margin against possible progressive failure triggered by hanger fracture if the improved hanger design has been adopted in the bridge.

From the comparison described in this section, it can be concluded that, when the conventional design method is adopted for the double-hanger anchorages in the througharch bridge, the bridge may be damaged by occasional local fracture of hangers. However, if the improved hanger design method is adopted, the bridge will still remain safe in case an occasional local fracture of hangers happens. The bridge still maintains a reasonable load-carrying capacity during an appropriate length of time to allow the necessary emergency measures to be taken.

\section{Conclusions}

The conventional design of double-hanger anchorages for through-arch bridges is reviewed from the structural robustness point of view. However, it is considered to improve neither the safety of the bridge nor the convenience of hanger replacement, since the identical hangers at an anchorage may fracture simultaneously and possibly induce progressive failure. An improved hanger design method involving the use of unequal hangers in a group with unequal initial stresses adjusted by proper jacking during erection is therefore put forward for better robustness. Finite-element models for an authentic through-arch bridge have been built up for dynamic analyses to evaluate the impact effects due to hanger fracture. It is found that the hangers and the parts of the longitudinal girder in the vicinity of the fractured hangers will experience the highest impact effects, while components further away are hardly affected. Although the smaller hanger in a group is expected to fail first, the hanger arrangement in the improved hanger design helps to preserve the load path of the structural system, and thereby helps to maintain the robustness of the bridge.

\section{Acknowledgements}

The present work is partly supported by the Independent Innovation Foundation of Shandong University, and the Small Project Funding and the HKU SPACE Research Fund of The University of Hong Kong, for which the authors are most grateful.

\section{REFERENCES}

Agarwal J, England J and Blockley D (2006) Vulnerability analysis of structures. Structural Engineering International: Journal of the International Association for Bridge and Structural Engineering (IABSE) 16(2): 124-128.

Alexander S (2004) New approach to disproportional collapse. The Structural Engineer 82(23): 14-18.

ANSYS (2010) Software, Release 13.0, ANSYS, Inc., Canonsburg, Pennsylvania, USA.

Bathe KJ (1996) Finite Element Procedures. Prentice Hall, Englewood Cliffs, NJ, USA.

Beeby AW (1999) Safety of structures and a new approach to robustness. The Structural Engineer 77(4): 16-21.

CEN (European Committee for Standardization) (2006) EN 19911-7: Eurocode 1: Actions on Structures: Part 1-7: Accidental Actions. CEN, France.

Ellingwood BR and Dusenberry DO (2005) Building design for abnormal loads and progressive collapse. ComputerAided Civil and Infrastructure Engineering 20(3): 194205.

General Services Administration (2003) Progressive Collapse Analysis and Design Guidelines for New Federal Office Buildings and Major Modernization Projects. General Services Administration, USA.

Gulvanessian H and Vrouwenvelder T (2006) Robustness and the eurocodes. Structural Engineering International: Journal of the International Association for Bridge and Structural Engineering (IABSE) 16(2): 167-171.

IStructE (Institution of Structural Engineers) (2002) Safety in Tall Buildings. IStructE, London, UK.

Jiang XF and Chen YY (2008) Review on the progressive collapse and control design of building structures. Tumu Gongcheng Xuebao/China Civil Engineering Journal 41(6): 1-8 (in Chinese).

Li DS, Zhou Z, Deng NC and Ou JP (2007) Fiber bragg grating sensors for arch bridge hanger health monitoring. In Kulchin YN, Ou JP, Vitrik OB and Zhou Z (eds), Fundamental Problems of Optoelectronics and Microelectronics III; Proc. SPIE 6595, 65952U-1-6.

Li HN, Gao DW and Yi TH (2008) Advances in structural health monitoring systems in civil engineering. Advances in Mechanics 38(2): 151-166 (in Chinese).

Li Y, Chen YY, Nie JG and Chen BC (2002) The Design and Application of the Composite Bridges. Science Press, Beijing, China (in Chinese).

MOHURD (Ministry of Housing and Urban-Rural Development of the People's Republic of China) (2003) Code for Design of 
Steel Structures, GB50017-2003. MOHURD, China

Planning Press, Beijing, China (in Chinese).

MTPRC (Ministry of Transport of People's Republic of China)

(2007) Guidelines for Design of Highway Cable-stayed

Bridges. MTPRC, China Communications Press, Beijing, China (in Chinese)

Pearson C and Delatte N (2005) Ronan point apartment tower collapse and its effect on building codes. Journal of Performance of Constructed Facilities 19(2): 172-

177.
Smith JW (2003) Energy approach to assessing corrosion damaged structures. Proceedings of the Institution of Civil Engineers - Structures and Buildings SB156(2): 21 130 .

Vlassis AG, Izzuddin BA, Elghazouli AY and Nethercot DA (2006) Design oriented approach for progressive collapse assessment of steel framed buildings. Structural Engineering International: Journal of the International Association for Bridge and Structural Engineering (IABSE) 16(2): 129-136.

\section{WHAT DO YOU THINK?}

To discuss this paper, please email up to 500 words to the editor at journals@ice.org.uk. Your contribution will be forwarded to the author(s) for a reply and, if considered appropriate by the editorial panel, will be published as discussion in a future issue of the journal.

Proceedings journals rely entirely on contributions sent in by civil engineering professionals, academics and students. Papers should be 2000-5000 words long (briefing papers should be 1000-2000 words long), with adequate illustrations and references. You can submit your paper online via www.icevirtuallibrary.com/content/journals, where you will also find detailed author guidelines. 